\title{
A study on management of learning of students in Higher Vocational Colleges based on the " broken windows effect "
}

\author{
Haiyan Zhen \\ Shandong Institute of Commerce and Technology, Jinan, 250103, China \\ email:13764660@qq.com
}

Keywords: Vocational Colleges; Learning Management; Broken windows Effect

\begin{abstract}
Along with the change of the college entrance examination system, the spring college entrance examination and the number of separate enrollment has expanded each year, Vocational colleges students increase in species ,and the quality of students is uneven. Vocational students in the study showed new features, based on the "broken windows effect" theoretical research, combined with new learning characteristics of students in vocational colleges' students, a management model of effective learning of students in vocational colleges is proposed.
\end{abstract}

\section{The introduction of "Broken window " theory}

"Broken windows effect" is a theory of criminology, which is putted forward by James Wilson and George Keeling. "Broken windows effect" theory: When a window glass in a building was shattered but did not get it timely repaired, others may get some kind of hint and then break more glasses. This theory suggests that if let the negative phenomena in the environment go unchecked, them will tempt people to emulate, and even intensified. The core of this theory is that "the first piece of broken glass should be repaired in time, or the broken glass will start to appear". It can be found that : for bad atmosphere, bad behavior, if we do not control and then eliminate in a timely manner, which will induce the occurrence of more similar behavior, and finally make the management in a state of confusion, out of control.

Knowledge Management refers to that through planning, organizing, leading, control and other means, using the method of management to make study procedural, streamlined and standardized, and create the best solutions so as to achieve the purpose of efficient learning. The theory and inspiration based on the "broken windows effect" theory is applied to the learning management for students in vocational colleges, which has an important practical significance.

\section{The new situation learning management of vocational college students face}

Along with the change of the college entrance examination system, college entrance examination from once a year to in addition to the traditional annual college entrance examination in June and increasing the spring college entrance and own entrance examination. From 2011, spring college entrance examination of Shandong province take the place of vocational exam in previous years, which is a unified entrance examination focus for secondary vocational school graduates, at the same time for high school graduates; mainly to help the vocational colleges to select qualified students. In the eyes of the students and parents in Shandong Spring, college entrance examination is just for the students who failed to pass the college entrance examination, rarely attended by good students. In 2012,about the spring college entrance examination in Shandong province, candidates from other provincial accounted for $70 \%$ above of graduate of average high school students attended it, which are mainly from the southern (Zhejiang, Yunnan, Kunming, etc.), and generally have a poor foundation. In nearly two years, the students who take separate entrance examination in higher vocational colleges of Shandong generally have poor results of basic courses, especially in math scores more than half of the students are below the pass line, what is worse, math scores of college entrance examination for some student is a digit. These students are even worse than secondary vocational school students' cultural foundation. Due to the emergence of this situation, learning behavior of students in vocational colleges during the past two 
years showed the new features:

1 Enrollment results show a declining trend year by year, basic courses' results are poor; achievements of students are quite different. In the same institutions or even the same class, the college entrance examination scores of students range from 200 to 500 points, students' learning ability has a big difference, and a large part of the students did not form good study habits. As the academic pressure decreases and the living environment of the university has a relaxed freedom, without the supervision of teachers and parents, the students' enthusiasm, initiative reduce, along with serious passive learning. Especially the students of vocational colleges lack of a planning for their future, there is a clear tendency towards utilitarianism learning: light theory and heavy practice in learning, so they do not pay attention to the usual accumulation, just learn by rote before the exam.

2 Self is not strictly required, a sense of discipline is weak, and poor is a sense of collective honor. Compared with students of normal universities, at the beginning of enrollment, students in higher vocational colleges have varying degrees of inferiority. Many of the students believe that there is no alternative for them to study in the Higher Vocational College. At the same time, failing to be admitted to the undergraduate college shows their poor performance in the learning. They lack of a good career planning for the future. They do not care whether they can master the relevant professional knowledge; just getting a diploma is a considerable part of the target. For the most of the students, their own requirements are not strict, and the sense of discipline and the sense of collective honor are poor. Through the investigation in a higher vocational colleges ,I found 57\% of the students do not have clear learning objectives and future plans; $45 \%$ of the students were once late; $52 \%$ of the students admitted that he occasionally missed a class, $21 \%$ of the students admitted often they were absent from school; $22 \%$ of the students

cheated on an examination; more than $70 \%$ of the students tested the shock as the main method of dealing with exam; only $20 \%$ of the students did not miss classes, did not be late, and completed the homework teacher assigned on time. Playing phone in class, playing games, playing poker after class, operating mutual plagiarism homework copied each other, cheating on exams become a common phenomenon.

3 In generally, the process of studying reflects the characteristics of light theory. They generally do not attach importance to the public basic courses such as mathematics, ideological and political theory courses. For the professional courses their learning enthusiasm is not so high, especially for the course which the teacher is not strictly to treat, students' late and absenteeism often are in a serious condition. Do not attach importance to the learning process, lack of the awareness of the importance of classroom teaching; to bone up before the exam is taken as the main way to deal with the exam.

These new features of learning of vocational students bring new challenges to the student's learning management. Generally the mode of learning management of vocational college students copy management mode for ordinary colleges and universities, but such an approach is contrary to the characteristics of the students in vocational colleges,

in terms of the foundation of learning, the habit of learning, students in ordinary colleges and universities and students in vocational colleges have a different attitude. So we can conclude it that the methods of learning the management mode for ordinary colleges and universities can be learned from, but cannot just be copied.

\section{The application of "broken windows effect"}

"Broken windows effect" theory as an important management theory has important implications in the learning management of students. "Broken windows effect" have a positive practical significance to enhance learning management of students in the higher vocational college, change school culture of learning, improve learning the efficiency of learning, and promote the cultivation of talents. Based on "Broken windows effect", combined with learning characteristics of students in vocational colleges, the following effective learning management mode is proposed.

1 Strengthen the construction of system, emphasis on the cost of breaking the rules so that students do not dare "broken windows". 
Establish and improve the system of learning management, which is scientific and suitable for the characteristics of students in the higher vocational college. Scientific learning management system is an important guarantee for students to study smoothly, is an important means to guide the students to develop students' sense of discipline and a strict style and to promote the formation of a good character of students. To establish a set of learning management system, which not only help to maintain the order of teaching and learning of students, but also help to develop students' concept of law-abiding, is an important aspect of management systems of the vocational colleges. Several aspects of the specific system are as follows, from the evaluations of performances in all subjects, the attendance of students, the discipline of class, the situation of completion of students' homework, and the management methods of examination discipline.

(1) Make the evaluations of performances in all subjects based on the heavy practical features of vocational colleges. In the learning management of Higher Applied Mathematics, for example: the attendance of students, the performance in class (20\%), regular assignments account for 20\%, accounting for $60 \%$ of your final grade. Strengthen the system of regular attendance and the discipline of class. 5 points is deducted for being late once, 10 points is deducted for be absence from school once, if a student was absent for 3 times, just the qualification of examination of the one will be canceled. 5 points is deducted for normally sleeping in class, a student playing mobiles in class will be deducted 5 points, and the qualification of examination will be canceled for sleeping and playing mobile phone for 5 times. At the same time, for the class cadres and ordinary students, they should be treated equally, never any personal privileges are allowed so that students in class can see a fair and impartial management system

(2) Pay a great attention to the management of assessment of learning process. Strictly control over the quality of students' completed homework, for not handing in their homework once results in a deduction of 10 points, and the qualification of examination will be canceled for not handing in their homework for 3 times. Copying homework for one time will result in a deduction of 10 points, and at the same time, For a student, if he or she copies homework for three times, the qualification of examination will be canceled.

(3) Establish a strict management system of the discipline of examination. Once cheating on the examination was found that test scores would be zero points, and qualification of this school year examination will canceled at the same time, only when graduation is approaching, a make-up exam will be allowed. Cheaters will be disqualified from all awards and awards.

2 Ensure the implementation of the system, take the attitude of "zero tolerance" and "fuss" approach on illegal phenomenon and timely repair the "broken windows".

A scientific system of learning management is important, but if there is no an effective execution and implementation of the system, the system only is on paper, as the dummy. "Broken windows effect" believes: "the first broken windows" is often the starting point of things getting worse. This phenomenon is often seen in everyday life. There are many examples of the "broken windows effect" in life. For example, both sides of a family's door were filled with flowers, for a long time flowers were very tidy and bright. One day a girl passing there found the flowers look so beautiful and picked one from the flowers, gradually more and more people picked flowers, eventually the flowerpot simply was moved out. As another example, in a clean square, people are embarrassed to throw scraps of paper or cigarette butts, but look for the trash. However, if the square is dirty, people will not hesitate to discard cigarette butts or scraps of paper on the ground without any sense of shame. More and more person like a tidal wave followed, along with just turning a blind eye to the red light and the traffic rules. In order to make the student's learning management perfect, taking the attitude of "zero tolerance" to such behaviors of being late, skipping school, sleeping in class, playing phone in class, copying homework, cheating on examination in the learning process is necessary. Pay a enough and full attention to the phenomenon of the first violation of system of learning management. When it is necessary, take the "fuss" approach, timely repair a broken window to prevent someone to emulate, so as to not achieve the degree of diehard.

\section{An investigation on the application effect of management model of Students learning based on the "broken window effect"}

I did some experiments in my own two classes in a vocational college. At the beginning of the 
term, the system of the learning management the above mentioned was announced to everyone in class so that all students in the class will have a full understanding with the system of the learning management. Such as the evaluations of performances in all subjects, the attendance of students, the discipline of class, the situation of completion of students' homework and the management methods of examination discipline and so on. In the first class, a strict mode of learning management was taken. The student who was the first violation of the system was given severe punishment and penalty. In public, his violation of the system of the learning management will be pointed. At the same time according to the provisions of the punishment in the system of learning management, some certain points were deducted. It is under the careful supervision of the whole class. For the violations of the system of the learning management, we had better take the attitude of "zero tolerance" .What's more, any students can not engage in any particular manner in any situation, and pay special attention to the repairing of "the first piece of broken glass ", in a timely manner the undesirable phenomena will be killed in the bud. And when it is an appropriate time, attitude of "Fuss" should be taken, namely, pay a special attention to repairing "the first piece of broken glass" timely. But in another class, the system of learning management was the same one, but the implementation of the system was not enough. One or two irregularities appeared, but could not be stopped timely, not deduct the specified points according to the system, just giving a simple verbal warning. After a semester, it was found in the first class which was strictly in accordance with the implementation of the system of learning management, only one student was late, just because that "the first piece of broken glass" was repaired in a timely manner, the implementation of learning management system played a good effect, at Acknowledgement the same time, the whole classmates formed a good sense of discipline in class, the phenomenon of tardiness and absenteeism never happened. The mental outlook of the whole class was good. However, in other class, the first student who was late for school was not be punished in accordance with the system of learning management, so more and more student were late for class. At last, collected statistics showed that more than $30 \%$ of the students were late for class for one time; more than $15 \%$ of the students missed a class for one time, the phenomenon of sleeping in class, coping homework and playing phone in class was also endless, what was worse, the spirit of students and enthusiasm of studying suffered a great negative impact.

As we can see from the "broken windows effect" that the environment not only has a binding force and but also has an inductivity. The existence of any kind of negative phenomena may be transmissions of a message which will lead to further negative phenomena continue to expand. According to characteristics of vocational students' learning, being vigilant against the irregularities which appear to be accidental, individual is necessary, If we turn a blind eye to those accidental and individual behavior and do not correct them in a timely manner, more and more people will condone to break the "glass", which is likely to evolve into a worse consequences: A small leak will sink a great ship. Fully aware of the adverse effects of the theroy "the first piece of broken glass" .in such a group of students with special features on the learning management of students studying in the vocational colleges, make full use of the theroy of "broken window effect" and in a timely manner correct the bad habits of the process of students' studying to improve the effectiveness of learning, What's more, it has an important role in the establishment of good learning atmosphere of the students in a whole class.

\section{References}

[1] Ping Chen, "The Inspiration of the "broken windows" theory for the construction of the style of study in Colleges and Universities ,” Literature, vol. 19, pp. 134, 2012

[2] Rong Huang, "A Introduction to the characteristics and management method of Students in Higher Vocational College ,” UNIONS.: Theory Research, vol. 10, pp. 132-133, 2010

[3] Fen $\mathrm{Xu}$, "The characteristics and the corresponding management method of Students in Higher Vocational College ,” Education article, vol. 15, pp. 41, 2008 